\title{
Gloves Perforations in Minor Oral Surgical Procedures: A Comparison of Latex and Nitrile Gloves
}

\author{
Ajeet Kumar ${ }^{1}$ \\ BDS, FCPS \\ Naveed Iqbal ${ }^{2}$ \\ BDS, FCPS \\ Javaria Farooq ${ }^{3}$ \\ BDS \\ Saad Uddin Siddiqui ${ }^{4}$ \\ BDS, MFDS
}

OBJECTIVE: This study was performed to compare incidence of perforations in Latex and Nitrile examination gloves during Minor Oral surgical procedures performed under local anesthesia.

METHODOLOGY: 100 pairs of latex and 100 pairs of Nitrile examination gloves where used to perform 200 minor oral surgical procedures under local anesthesia. After completion of every minor oral surgical procedure each gloves was examined by Water Inflation method to observe presence or absence of Perforations. A data sheet was used to collect data including type of Gloves used (Latex or Nitrile) presence of perforations, sites of perforations and nature of minor oral surgical procedures.

Data was entered and analyzed using SPSS version 20. Descriptive analysis was conducted to calculate frequency and percentages of Number and sites of perforations for both Nitrile and latex examination gloves. Chi Square test was used to find out statistical significance of difference of perforations rate between Nitrile and Latex gloves. P value of $<0.05$ was considered significant. RESULTS: Out of 200 latex gloves 23 (11.5) had 29 perforations whereas out of total 200 Nitrile gloves 28 (14\%) had 22 perforations. Nitrile gloves had a statistically significant higher rate of perforations as compared to Latex gloves. (P value 0.043). For both Nitrile and Latex gloves left non dominant hand had highest frequency of perforations Latex 18 (81.81\%) perforations and Nitrile 18(62.06\%). Index finger and thumb were most frequent sites of perforations in both Latex and Nitrile gloves.

CONCLUSION: Gloves perforations were more common in Nitrile examination gloves however total number of perforations was more in Latex examination gloves.

KEYWORDS: Glove perforation, minor oral surgery, cross infection control.

HOW TO CITE: Kumar A, Iqbal N, Farooq J, Siddiqui SU. Gloves perforations in minor oral surgical procedures: a comparison of latex and nitrile gloves. J Pak Dent Assoc 2021;30(2):103-106.

DOI: https://doi.org/10.25301/JPDA.302.103

Received: 14 November 2020, Accepted: 25 February 2021

\section{INTRODUCTION}

$\mathrm{P}$ revention of Cross infection is the utmost important objective in dentistry. Use of PPEsincluding Mask, Surgical Gowns, Eyewear and Gloves has been in practice to reduce risk of cross infection transmission. ${ }^{1}$ Latex gloves were first produced by Dr. William Halsted in 1892 and since than gloves have become integral part of medical and surgical cross infection control protocols. ${ }^{2}$ In the year, 1991 SHOWAN international company developed Nitrile Gloves. Nitrile gloves were made to solve the risk

1. Assistant Professor and Head, Department of Oral \& Maxillofacial Surgery, Sir Syed College of Medical Sciences, (Dental Section), Karachi.

2. Assistant Professor, Department of Oral \& Maxillofacial Surgery, Sir Syed College of Medical Sciences, (Dental Section), Karachi.

3. FCPS II Resident, Department of Orthodontics, Dr Irshad-ul-Ebad Institute of Oral Health Sciences, Dow University of Health Sciences, Karachi.

4. Assistant Professor, Department of Oral Medicine, Dow Dental College, Dow University of Health Sciences, Karachi

Corresponding author: “Dr. Naveed Iqbal syed” < naveedtariqsyed@gmail.com > of allergy associated with Latex gloves. ${ }^{2}$ In vitro studies had proven that Nitrile gloves have higher puncture resistance and stiffness. ${ }^{4,5}$ A study conducted by Rego and Roley to observe barrier integrity of Nitrile and latex had confirmed that after manipulations both Nitrile and Latex performed significantly better as compared to Vinylgloves. ${ }^{6}$

Perforations of gloves during surgery could result in cross infections and contamination of surgical wounds. In dentistry rate of gloves perforation can range from $4 \%$ to $7.5 \%,{ }^{7,8}$ whereas major maxillofacial surgical procedures are associated higher risk of gloves perforations. ${ }^{9}$ A study by Priya etal at Jamshoro had proved that major oral surgical procedures had highest incidence of gloves perforations. ${ }^{10}$ Fully Saraiva etal compared Surgical and procedural gloves for rate of perforations after dental procedures, they observed that surgical latex gloves had 14 perforations $(38.9 \%)$ and Procedural latex gloves had 92 perforations (38\%). ${ }^{11}$

Murray et al assessed use of Nitrile gloves in clinical dentistry. Their study had proven that after clinical use only 
$1.9 \%$ of Latex gloves had punctures as compared to Nitrile, which had $5.3 \%$ puncture rate. $^{12}$

This study was performed to compare PPEs integrity and endurance of Latex and Nitrile gloves after minor oral surgical procedures. The results of this study would be helpful for Oral surgeons and dentists in general as well in choosing suitable type of gloves for minor oral surgical procedures.

The hypothesis of this study is Nitrile Gloves has less number of perforations as compared to Latex gloves in minor oral surgical procedures.

\section{METHODOLOGY}

This prospective observational study was conducted at the outpatient Department of Oral and Maxillofacial Surgery, Sir Syed Dental Hospital Karachi from 29 December 2019 to 28 July 2020. After attaining approval from Ethical review board of the hospital 100 pairs of Latex examination gloves (200 gloves) (Disposable Latex examination gloves ISO 9001:2008) and 100 pairs (200 gloves) of Nitrile examination gloves were used by two Right handed oral and maxillofacial surgeons to perform various minor oral surgical procedures. Sample size was calculated using minimum $4 \%$ and maximum 50\% perforation rat of gloves reported by Xavier as reference minimum sample size was determined 200 gloves with a power of $80 \%=0.05$ error and $95 \%$ confidence interval. Both surgeons had equal experience and qualification in the field of Oral and maxillofacial Surgery.

Oral surgical procedures, which were included in study, are surgical extractions of impacted third molars, Alveoloplasty, drainage of abscess, Management of dentoalveolar trauma, and excision of epulis and other benign soft tissue reactive lesions under local anesthesia in outpatient department. Simple extractions under local anesthesia, surgical extractions of other teeth under local anesthesia and major oral surgical procedure, which were performed under general anesthesia, were excluded. After completion of every minor oral surgical procedure, gloves were carefully removed by each operator and placed in a disposable plastic bag. Each pair of gloves was assessed for perforations using Water inflation method ${ }^{9}$ in this method gloves were filled with $500 \mathrm{ml}$ water after which gentle pressure was applied to locate number and site of perforations in each glove. Fifty Nitrile and Fifty Latex unused gloves were also tested as controls to detect any preexisting punctures and defects in gloves. Data including type of minor oral surgical procedure performed, presence of perforation, number and locations of perforations was recorded on a profroma. Data was entered and analyzed using SPSS version 20. Descriptive analysis was performed to calculate frequencies and percentages of site and quantity of glove punctures in each hand and finger. Chi Square test was used to find out the statistical significance of difference in the rate of perforations between Nitrile and Latex gloves. $\mathrm{P}$ value of $<0.05$ was considered statistically significant (95\% confidence interval).

\section{RESULTS}

Two hundred latex and 200 Nitrile gloves were assessed by Water inflation method to determine rate of punctures after completion of each minor oral surgical procedure. Out of 200 latex gloves 23 (11.5) had 29 puctures whereas out of total 200 Nitrile gloves $28(14 \%)$ had 22 punctures. Nitrile gloves had a statistically significant higher rate of puctures as compared to Latex gloves. (P value 0.043) see Table 1. For both Nitrile and Latex, gloves left non-dominant hand had highest frequency of perforations Latex 19 (65.51\%) perforations and Nitrile 12(54.54\%). Index finger and thumb were most frequent sites of perforations in both Latex and Nitrile gloves. See Table 2

Table 1: Frequency of gloves punctures in both Latex and Nitrile gloves

\begin{tabular}{|l|l|l|l|c|}
\hline $\begin{array}{l}\text { Type of } \\
\text { Gloves }\end{array}$ & Number of Gloves used & $\begin{array}{l}\text { Frequency of } \\
\text { perforations }\end{array}$ & $\begin{array}{l}\text { Total number of } \\
\text { punctures }\end{array}$ & Percentage \\
\hline Latex & 200 & 23 gloves & 29 & $11.5 \%$ \\
\hline Nitrile & 200 & 28 gloves & 22 & $14 \%$ \\
\hline Total & 400 & 51 Gloves & 51 Punctures & $25.5 \%$ \\
\hline
\end{tabular}

Table 2: Distribution of sites of perforation in Nitrile and Latex gloves

\begin{tabular}{|l|c|c|c|}
\hline Sites of perforations & $\begin{array}{l}\text { Nitrile examination } \\
\text { Gloves }\end{array}$ & $\begin{array}{l}\text { Latex examination } \\
\text { Gloves }\end{array}$ & Total \\
\hline Left hand Thumb & $10(45.45 \%)$ & $08(27.58 \%)$ & $18(35.29 \%)$ \\
\hline Left hand index Finger & $05(22.72 \%)$ & $04(13.79 \%)$ & $09(17.64 \%)$ \\
\hline Left hand middle finger & $02(9.09 \%)$ & $04(13.79 \%)$ & $06(11.76)$ \\
\hline Left hand ring finger & $01(4.54 \%)$ & $01(3.44 \%)$ & $02(3.92 \%)$ \\
\hline Left hand little finger & 00 & $01(3.44 \%)$ & $01(1.96 \%)$ \\
\hline Total & $18(81.81 \%)$ & $18(62.06 \%)$ & $36(70.58 \%)$ \\
\hline Right hand Thumb & $02(9.09 \%)$ & $02(6.89 \%)$ & $04(7.84 \%)$ \\
\hline Right hand index finger & $01(4.54 \%)$ & $03(10.34 \%)$ & $04(7.84 \%)$ \\
\hline Right hand middle finger & $01(4.54 \%)$ & $02(6.89 \%)$ & $03(5.88 \%)$ \\
\hline Right hand ring finger & $00(0 \%)$ & $02(6.89 \%)$ & $02(3.92 \%)$ \\
\hline Right hand little finger & $00(0 \%)$ & $02(6.89 \%)$ & $02(3.92 \%)$ \\
\hline Total & 22 & 29 & $51(100 \%)$ \\
\hline
\end{tabular}

\section{DISCUSSION}

Our study had determined that gloves perforations were more commonly found in Nitrile gloves had statistically significant $(\mathrm{P}=0.043)$ higher rate of perforations ( 28 gloves with 22 perforations) as compared to Latex examination gloves (23 gloves with 29 perforations) as assessed by water inflation method after completion of Minor Oral 
Surgical procedures under local anesthesia. It was noted that although more Nitrile examination gloves were punctured but number of perforations were more in Latex examination gloves. Oral and Maxillofacial surgery involves use of several sharp instruments, needles and wires that's why risk of cross contamination is higher during major oral surgical procedures. A study by Kuroyanagi etal had reported that Orthognathic surgical procedures were associated with highest incidence of latex gloves punctures $91.1 \%$ followed by cleft palate repair $55.0 \% .{ }^{13}$ However, in current study, we only assessed rate of latex and Nitrile examination gloves perforations in minor oral surgical procedures performed in outpatient department under local anesthesia. A study by Xavier etal had assessed rate of surgical latex gloves perforations after surgical extractions. Which were performed by residents and undergraduate students. Study had found that out of 200 surgical latex gloves $16(8 \%)$ had perforations. ${ }^{14}$ our findings are in variance with their results as we had used Latex and Nitrile examination gloves which are thinner than Latex surgical gloves. However, a study by Bagget and Bruke had discovered 16\% rate of gloves perforations after surgical extractions ${ }^{8}$, findings of this study can compared with our results. Some previous studies had found that Nitrile gloves were superior to Latex gloves when examined for physical integrity, but most of these studies were in vitro experiments ${ }^{4,15}$, in published literature, no study had compared Nitrile and Latex gloves for status of physical integrity after oral surgical procedures. A study by Murray et al had compared rate of Nitrile and Latex gloves punctures after routine dental procedures. Their study had reported statistically significant $(\mathrm{P}<0.0001)$ higher rates of punctures in Nitrile gloves as compared to latex gloves. ${ }^{12}$ It was revealed by previous studies that most Gloves perforations were found in Non dominant usually left hand of the operators. ${ }^{8,9}$ The of findings this study are in agreement with these studies, we had observed most gloves perforations in non -dominant left hand for both nitrile and latex gloves. In previous studies, it was determined that most gloves perforations had occurred in Index finger and thumb regions of the gloves ${ }^{8,14}$ our findings are consistent with these studies. This study had recorded that larger number of perforation were seen in Thumb and index finger areas of both Latex and Nitrile gloves. Phadeya et al had recommended the use of sterile double surgical gloves in minor and major oral surgical procedures, to reduce risk of infection transmission and needle stick injuries. ${ }^{16}$ Patel etal after conducting an in vitro experiment had recommended that Nitrile gloves had higher stiffness and puncture resistance as compared to Latex gloves however; Latex gloves had an ability to reseal itself due to its higher elasticity. ${ }^{17}$

\section{CONCLUSION}

The findings of our study had observed that nitrile gloves perforations are more likely to occur during minor surgical procedures especially surgical extraction of impacted wisdom teeth.

In this study, we had observed that Latex gloves were superior to Nitrile in terms of barrier breach. Latex gloves are acclaimed for their better tear resistance, intermediate abrasion resistance and effective virus impermeability. Whereas Nitrile gloves have intermediate tear resistance, strong abrasion resistance and poor virus impermeability.

\section{RECOMMENDATIONS}

We recommend that never depend solely on fragile gloves and as recommended by Zatreeh et al, careful surgical technique, meticulous handling of instruments and application of controlled force should not be ignored during surgery. ${ }^{18}$

In order to prevent cross contamination and needle stick injuries, in oral and maxillofacial surgery several methods could be adopted, including use of sterile surgical gloves, double latex gloves, Nitrile gloves and frequent change of gloves during prolong oral surgical procedures.

\section{CONFLICT OF INTEREST}

None to declare

\section{REFERENCES}

1. Laheij A, Kistler JO, Belibasakis GN, Valimaa H, de Soet JJ. Health care associated viral and bacterial infections in dentistry. J Oral Microbiol. 2012;4:10:176-97

https://doi.org/10.3402/jom.v4i0.17659

2. Crippa M, Belleri L, Mistrello G, Tedoldi C, Alessio L.Prevention of latex allergy among health care workers and in the general population: latex protein content in devices commonly used in hospitals and general practice. Int Arch Occup Environ Health. 2006;79:550-57. https://doi.org/10.1007/s00420-005-0080-5

3. M. Mansouri, M. Tidley, K. A. Sanati, C. Roberts, Comparison of blood transmission through latex and nitrile glove materials, Occupational Med, 2010:60;3:205-21

4. Rego A, Roley L. In-use barrier integrity of gloves: Latex and nitrile superior to vinyl. Am J Infect Control. 1999; 27:405-10.

https://doi.org/10.1016/S0196-6553(99)70006-4

5. UK Health Departments. Guidance for clinical healthcare workers: protection against infection with blood-borne viruses. Wetherby: Department of Health, 1998. 
6. Phalen RN, Wong WK. Integrity of disposable nitrile exam gloves exposed to simulated movement. J Occup Environ Hyg. 2011; 8: 289-99.

https://doi.org/10.1080/15459624.2011.569285

7. Baggett FJ, Burke FJT, Wilson NHF. An assessment of the incidence of punctures in gloves when worn for routine operative procedures. Br Dent J 1993;174:412-16.

https://doi.org/10.1038/sj.bdj.4808187

8. Burke FJT, Baggett FJ, Lomax AM. Assessment of the risk of glove punctures during oral surgery procedures. Oral Surg Oral Med Oral Pathol Oral Radiol Endod 1996;82:18-21. https://doi.org/10.1016/S1079-2104(96)80372-6

9. Khan M, Bagg PR. Glove perforations during Oral and Maxillofacial surgical procedures. Pak Oral Dent J. 2016; 71:223-27.

10. Priya, Banglani MA, Punjabi SK, Parveen S. Gloves punctures in general dentistry. Professional Med J. 2019;26:1760-764.

https://doi.org/10.29309/TPMJ/2019.26.10.4137

11. Fully Thália Líbni Costa Saraiva, Lucena Eudes Euler de Souza, Dias Tasiana Guedes de Souza, Barbalho Jimmy Charles Melo, Lucena Vicente Cleiton Ferreira, Morais Hécio Henrique de Araújo. Glove perforations after dental care. RGO, Rev. Gaúch. Odontol. [Internet]. 2015 June [cited 2020 Aug 14] ; 63:175-180 https://doi.org/10.1590/1981-863720150002000062823

12. Murray CA, Burke F, Mchugh S. An assessment of the incidence of punctures in latex and non- latex dental examination gloves in routine clinical practice. Brit Dent J. 2001;31:15-20.

https://doi.org/10.1038/sj.bdj.4800978

13. Kuroyanagi N, Nagao T, Sakuma H, Miyachi H etal. Risk of surgical glove perforation in oral and maxillofacial surgery. Int J Oral Maxillofac Surg. 2012; 41:1014-019. https://doi.org/10.1016/j.ijom.2012.02.010

14. Xavier RL, Vasconcelos BC, da Silva LC, Porto GG. Glove perforation during oral surgical procedures. Med Oral Patol Oral Cir Bucal. 2006;11:E433-E436.

15. Phalen RN, Wong WK. Tensile properties and integrity of clean room and low-modulus disposable nitrile gloves: a comparison of two dissimilar glove types. Ann Occup Hyg. 2012;56:450-57.

16. Patel, H., Fleming, G. \& Burke, F. Puncture resistance and stiffness of nitrile and latex dental examination gloves. Br Dent J. 2004;196: 695-700.

https://doi.org/10.1038/sj.bdj.4811353

17. Padhye MN, Girotra C, Khosla AR, Gupta KV. Efficacy of double gloving technique in major and minor oral surgical procedures: A prospective study. Ann Maxillofac Surg. 2011;1:112-19. https://doi.org/10.4103/2231-0746.92771

18. Zaatreh S, Enz A, Klinder A, et al. Prospective data collection and analysis of perforations and tears of latex surgical gloves during primary endoprosthetic surgeries. GMS Hyg Infect Control. 2016;11:Doc25. 